\title{
The Possibility of Error
}

On ne sert dignement la philosophie qu'avec le même feu qu'on sent pour une maîtresse.-Rousseau, Nouvelle Helöise.

We have before us our theorem, and an outline of its proof. We are here to expand this argument. We have some notion of the magnitude of the issues that are at stake. We had found ourselves baffled in our search for a certainty by numerous difficulties. We had found only one way remaining so far quite clear. That was the way of postulating what the moral consciousness seems to demand about the world beyond experience. For many thinkers since Kant, that way has seemed in fact the only one. They live in a world of action. "Doubt," they say, "clouds all theory. One must act as if the world were the supporter of our moral demands. One must have faith. One must make the grand effort, one must risk all for the sake of the great prize. If the world is against us, still we will not admit the fact until we are crushed. If the cold reality cares naught for our moral efforts, so be it when we come to know the fact, but meanwhile we will act as if legions of angels were ready to support our demand for whatever not our selfish interest, but the great interest of the Good, requires." Such is the view of the men whose religion is founded upon a Postulate.

We, too, felt that such faith is religious. We were willing to accept it, if nothing better could be found. But we were not content with it. Life has its unheroic days, when mere postulates fail

[Reprinted from RAP, pp. 384-435.] 
us. At such times we grow weary of toiling, evil seems actually triumphant, and, worse than all, the sense that there really is any perfect goodness yet unattained, that there is any worth or reason in our fight for goodness, seems to desert us. And then it will indeed be well if we can get for ourselves something more and better than mere postulates. If we cannot, we shall not seek to hide the fact. Better eternal despondency than a deliberate lie about our deepest thoughts and their meaning. If we are not honest, at least in our philosophy, then are we wholly base. To try once more is not dishonest.

So we did make the effort, and, in the last chapter, we sketched a result that seemed nearly within our reach. An unexpected result this, because it springs from the very heart of skepticism itself. We doubted to the last extremity. We let everything go, and then all of a sudden we seemed to find that we could not lose one priceless treasure, try as we would. Our wildest doubt assumed this, namely, that error is possible. And so our wildest doubt assumed the actual existence of those conditions that make error possible. The conditions that determine the logical possibility of error must themselves be absolute truth, that was the treasure that remained to us amid all our doubts. And how rich that treasure is, we dimly saw in the last discussion. That dim insight we must now try to make clearer. Perhaps our previous discussion has shown us that the effort is worth making.

Yet of one thing the reader shall be warned. The path that we travel is hereabouts very thorny and stony. It is a path of difficult philosophical investigation. Nobody ought to follow it who does not desire to. We hope that the reader will skip the whole of this chapter unless he wants to find even more of dullness than the rest of this sleepy book has discovered to him. For us, too, the arid way would seem hard, were it not for the precious prize at the end of it.

The story of the following investigation shall first be very briefly told. The author had long sought, especially in the discussions of Kant's "Kritik," and in the books of the post-Kantians, for help in seeing the ultimate principles that lie at the basis of knowledge. $\mathrm{He}$ had found the old and well-known troubles. Experience of 
itself can give no certainty about general principles. We must therefore, said Kant, bring our own principles with us to experience. We know then of causation, because causation is a fundamental principle of our thought, whereby we set our experience to rights. And so long as we think, we shall think into experience the connection of cause and effect, which otherwise would not be there. But hereupon the questions arose that have so often been asked of Kant and the Kantians. Why just these principles and no others? "That is inexplicable," replies Kant. Very well, then, suppose we give up applying to experience those arbitrary principles of ours. Suppose we choose to stop thinking of experience as causally connected. What then? "But you cannot stop," says Kant, "Your thought, being what it is, must follow this one fashion forever." Nay, we reply, how knowest thou that, Master? Why may not our thought get a new fashion some day? And then what is now a necessary principle, for example, that every event has a cause, would become unnecessary or even nonsensical. Do we then know a priori that our a priori principles must always remain such? If so, how come we by this new knowledge?

So Kant leaves us still uncertain about any fundamental principles upon which a sure knowledge of the world can be founded.

Let us, then, examine a little deeper. Are there any certain judgments possible at all? If one is skeptical in a thorough-going way, as the author tried to be, he is apt to reach, through an effort to revise Kant's view, a position something like the following,-a provisional position of course, but one that results from the effort to accept nothing without criticism: "Kant's result is that our judgments about the real world are founded on an union of thought and sense, thought giving the appearance of necessity to our judgment, sense giving the material. The necessity of any judgment amounts then only to what may be summed up in the words: So the present union of thought and sense makes things appear. If either thought or sense altered its character, truth would alter. Hence every sincere judgment is indeed true for the moment in which it is made, but not necessarily true for other moments. We only postulate that it is true for other moments." "And so," to continue this view, "it is only by means of postulates that our thought even seems to have any unity from moment to moment. We live in the present. If our thought has other truth or falsity than this, we do not know it. Past and future exist not for this 
present. They are only postulated. Save as postulated, they have no present meaning."

When he held and expressed this view, the author is free to admit that he was not always clear whether he ought to call it the doctrine of the relativity of truth or not. It might have avoided the absurdities of total relativity by taking form as a doctrine that the present moment's judgment is really true or false, for a real past and future, but that we, being limited to present moments, can never compare our judgments with reality to find whether our judgments are true or false. But although this interpretation is possible, this view often did express itself for the author as the doctrine of the total relativity of truth. The latter doctrine to be sure has no real meaning, but the author used with many others to fancy that it had.

To apply the view to the case of causal relations. "We continually postulate," the author used to point out, "we demand, without being able to prove it, that nature in future shall be uniform." So, carrying out this thought, the author used to say: "In fact future nature is not given to us, just as the past is not given to us. Sense-data and thought unite at every instant afresh to form a new judgment and a new postulate. Only in the present has any judgment evident validity. And our postulate of causal relation is just a way of looking at this world of conceived past and future data. Such postulates avoid being absurd efforts to regulate independent facts of sense, because, and only because, we have in experience no complete series of facts of sense at all, only from moment to moment single facts, about which we make single judgments. All the rest we must postulate or else do without them." Thus one reaches a skepticism as nearly complete as is possible to any one with earnest activity of thought in him. From moment to moment one can be sure of each moment. All else is postulate.

From the depths of this imperfectly defined skepticism, which seemed to him provisionally the only view he could adopt, the author escaped only by asking the one question more: "If everything beyond the present is doubtful, then how can even that doubt be possible?" With this question that bare relativity of the present moment is given up. What are the conditions that make doubt logically intelligible? These conditions really transcend the present moment. Plainly doubt implies that the statement doubted may be false. So here we have at least one supposed general truth, 
namely, "All but the immediate content of the present moment's judgment, being doubtful, we may be in error about it." But what then is an error? This becomes at once a problem of exciting interest. Attacking it, the author was led through the wilderness of the following argument.

\section{II}

Yet before we undertake this special examination of the nature of error, the reader must pardon us for adding yet another explanatory word. The difficulty of the whole discussion will lie in the fact that we shall be studying the possibility of the plainest and most familiar of commonplaces. Common sense hates to do such things, because common sense thinks that the whole matter is sure from the outset. Common sense is willing to ask whether God exists, but unwilling to inquire how it is possible that there can exist an error about anything. But foreseeing that something is to follow from all this, we must beg common sense to be patient. We have not the shadow of doubt ourselves about the possibility of error. That is the steadfast rock on which we build. Our inquiry, ultra-skeptical as it may at moments seem, is into the question: How is the error possible? Or, in other words: What is an error? Now there can be little doubt that common sense is not ready with any general answer to such a question. Error is a word with many senses. By error we often mean just a statement that arouses our antipathy. Yet we all admit upon reflection, that our antipathy can neither make nor be used to define real error. Adam Smith declares, with common sense on his side, in his "Theory of the Moral Sentiments," 1 that: "To approve or disapprove of the opinions of others is acknowledged, by everybody, to mean no more than to observe their agreement or disagreement with our own." Yet no one would accept as a definition of error the statement that: Error is any opinion that I personally do not like. Error has thus a very puzzling character. For common sense will readily admit that if a statement is erroneous, it must appear erroneous to every "right mind" that is in possession of the facts. Hence the personal taste of one man is not enough to define it. Else there might be as many sorts of error as there are minds. It is only the "right mind" whose personal taste shall decide what is an error in

1 Part I., sect. i., chap. iii, near the beginning. 
any particular case. But what then is a normal mind? Who is the right-minded judge? There seems to be danger that common sense shall run at this point into an infinite regress. I say: That opinion is an error. What do I mean? Do I mean that I do not like that opinion? Nay, I mean more. I mean that I ought not to like or to accept it. Why ought I not? Because the ideally right-minded person would not, seeing the given facts, hold that opinion about them. But who is the ideally right-minded person? Well, common sense may answer, It is my ideal person, the right-minded man as I conceive him. But why is my ideal the true ideal? Because I like it? - Nay, because, to the ideal judge, that kind of mind would seem the ideal. But who is the ideal judge? And so common sense is driven from point to point, unable to get to anything definite.

So much, then, to show in general that common sense does not know what an error is, and needs more light upon the subject. Let common sense not disturb us, then, in our further search, by the constant and indignant protest that error must somehow exist, and that doubt on that subject is nonsense. Nobody has any doubts on that subject. We ask only bow error exists and how it can exist.

For the rest, what follows is not any effort to demonstate in fair and orderly array, from any one principle or axiom, what must be the nature of error, but to use every and any device that may offer itself, general analysis, special example, comparison and contrast of cases,-anything that shall lead us to the insight into what an error is and implies. For at last, immediate insight must decide.

We shall study our problem thus. We shall take either some accepted definition of error, or some special class of cases, and we shall ask: How is error in that case, or in accordance with that definition, possible? Since error plainly is possible in some way, we shall have only to inquire: What are the logical conditions that make it possible? We shall take up the ordinary suppositions that common sense seems to make about what here determines the possibility of error. We shall show that these suppositions are inadequate. Then the result will be that, on the ordinary suppositions, error would be impossible. But that result would be absurd, if these were the only possible suppositions. Hence the ordinary suppositions must somehow be supplemented. When, therefore, we seem to say in the following that error is impossible, we shall mean only, impossible under the ordinary suppositions of common sense. What supplement we need to these suppositions, our argument will 
show us. In sum we shall find the state of the case to be this: Common sense regards an assertion as true or as false apart from any other assertion or thought, and solely in reference to its own object. For common sense each judgment, as a separate creation, stands out alone, looking at its object, and trying to agree with it. If it succeeds, we have truth. If the judgment fails, we have error. But, as we shall find, this view of common sense is unintelligible. A judgment cannot have an object and fail to agree therewith, unless this judgment is part of an organism of thought. Alone, as a separate fact, a judgment has no intelligible object beyond itself. And therefore the presuppositions of common sense must be supplemented or else abandoned. Either then there is no error, or else judgments are true or false only in reference to a higher inclusive thought, which they presuppose, and which must, in the last analysis, be assumed as Infinite and all-inclusive. This result we shall reach by no mystical insight, by no revelation, nor yet by any mere postulate such as we used in former discussions, but by a simple, dry analysis of the meaning of our own thought.

The most formidable opponent of our argument will be, after all, however, not common sense, but that thought mentioned in the last chapter,-the thought that may try to content itself with somewhat plausible jargon, and to say that: "There is no real difference between truth and error at all, only a kind of opinion or consensus of men about a conventional distinction between what they choose to call truth and what they choose to call error." This view, as the author has confessed, he once tried to hold. Still this meaningless doctrine of relativity is not the same as the view that contents itself with the postulates before discussed. That view might take, and for the author at one time did take, the possible and intelligible form thus expressible: "Truth and error, though really distinguishable, are for us distinguished only through our postulates, in so far as relates to past and future time." Such views, while not denying that there is real truth, despair of the attainability for us of more than momentary truth. But the doctrine of Total Relativity, this view above expressed, differs from genuine skepticism. It tries to put even skepticism to rest, by declaring the opinion, that there is error, to be itself an error. This is not merely a moderate expression of human limitations, but jargon, and therefore formidable, because jargon is always unanswerable. When the famous Cretan declared all statements made by Cretans to be in all cases lies, his 
declaration was hard to refute, because it was such honest-seeming nonsense. Even so with the statement that declares the very existence of error to be an erroneously believed fancy. No consensus of men can make an error erroneous. We can only find or commit an error, not create it. When we commit an error, we say what was an error already. If our skeptical view in previous chapters seemed to regard truth and error as mere objects of our postulates, that was only because, to our skepticism, the real truth, the real error, about any real past and future, seemed beyond our reach, so that we had to content ourselves with postulates. But that real error exists is absolutely indubitable.

This being the case, it is evident that even the most thoroughgoing skepticism is full of assumptions. If I say, "There may be no money in that purse yonder," I assume the existence of the purse yonder in order to make just that particular doubt possible. Of course, however, just that doubt may be rendered meaningless by the discovery of the actual non-existence of that particular purse. If there is no purse yonder, then it is nonsensical either to affirm or to deny that it contains money. And so if the purse of which I speak is an hallucination of mine, then the doubt about whether, as an actually existent purse, it has money in it, is deprived of sense. My real error in that case would lie in supposing the purse itself to exist. If, however, I abandon the first doubt, and go on to doubt the real existence of the purse, I equally assume a room, or some other environment, or at all events the universe, as existent, in order to give sense to my question whether the purse has any being in this environment or in this universe. But if I go yet further, and doubt whether there is any universe at all outside of my thought, what does my doubt yet mean? If it is to be a doubt with any real sense, it must be a doubt still with an object before it. It seems then to imply an assumed order of being, in which there are at least two elements, my lonely thought about an universe, and an empty environment of this thought, in which there is, in fact, no universe. But this empty environment, whose nature is such that my thought does wrong to suppose it to be an universe, what is that? Surely if the doubt is to have meaning, this idea needs further examination. The absolute skepticism is thus full of assumptions.

The first European thinker who seems to have discussed our present problem was Plato, in a too-much-neglected passage of the "Theætetus," ${ }^{2}$ where Socrates, replying to the second definition of 
knowledge given by Theætetus, namely, knowledge is True Opinion, answers that his great difficulty has often been to see how any opinion can possibly be false. The conclusion reached by Plato is no very definite one, but the discussion is deeply suggestive. And we cannot do better here than to pray that the shade of the mighty Greek may deign to save us now in our distress, and to show us the true nature of error.

\section{III}

Logicians are agreed that single ideas, thoughts viewed apart from judgments, are neither true nor false. Only a judgment can be false. And if a reasoning process is said to be false, the real error lies still in an actual or suppressed assertion. A fallacy is a false assertion that a certain conclusion follows from certain premises. Error is therefore generally defined as a judgment that does not agree with its object. In the erroneous judgment, subject and predicate are so combined as, in the object, the corresponding elements are not combined. And thus the judgment comes to be false. Now, in this definition, nothing is doubtful or obscure save the one thing, namely, the assumed relation between the judgment and its object. The definition assumes as quite clear that a judgment has an object, wherewith it can agree or not agree. And what is meant by the agreement would not be obscure, if we could see what is meant by the object, and by the possession of this object implied in the pronoun its. What then is meant by its object? The difficulties involved in this phrase begin to appear as soon as you look closer. First then the object of the assertion is as such supposed to be neither the subject nor the predicate thereof. It is external to the judgment. It has a nature of its own. Furthermore, not all judgments have the same object, so that objects are very numerous. But from the infinity of real or of possible objects the judgment somehow picks out its own. Thus then for a judgment to have an object, there must be something about the judgment that shows what one of the external objects that are beyond itself this judgment does pick out as its own. But this something that gives the judgment its object can only be the intention wherewith the judgment is accompanied. A judgment has as object only what it intends to have as object. It has to conform only to that to which it wants to con-

2 Plato, $T$., p. 187 sqq. 
form. But the essence of an intention is the knowledge of what one intends. One can, for instance, intend a deed or any of its consequences only in so far as he foresees them. I cannot be said to intend the accidental or the remote or even the immediate consequences of anything that I do, unless I foresaw that they would follow; and this is true however much the lawyers and judges may find it practically necessary to hold me responsible for these consequences. Even so we all find it practically useful to regard one of our fellows as in error in case his assertions, as we understand them, seem to us to lead to consequences that we do not approve. But our criticisms of his opinions, just like legal judgments of his acts, are not intended to be exact. Common sense will admit that, unless a man is thinking of the object of which I suppose him to be thinking, he makes no real error by merely failing to agree with the object that $I$ have in mind. If the knights in the fable judge each other to be wrong, that is because each knight takes the other's shield to be identical with the shield as he himself has it in mind. In fact neither of them is in error, unless his assertion is false for the shield as he intended to make it his object.

So, then judgments err only by disagreeing with their intended objects, and they can intend an object only in so far forth as this object is known to the thought that makes the judgment. Such, it would seem, is the consequence of the common-sense view. But in this case a judgment can be in error only if it is knowingly in error. That also, as it seems, follows from the common-sense suppositions. Or, if we will have it in syllogistic form:-

Everything intended is something known. The object even of an erroneous judgment is intended. $\therefore$ The object even of an error is something known.

Or: Only what is known can be erred about. Nor can we yet be content with what common sense will at once reply, namely, that our syllogism uses known ambiguously, and that the object of an erroneous judgment is known enough to constitute it the object, and not enough to prevent the error about it. This must no doubt be the fact, but it is not of itself clear; on the contrary, just here is the problem. As common sense conceives the matter, the object of a judgment is not as such the whole outside world of common sense, with all its intimate interdependence of facts, with all its unity in the midst of diversity. On the contrary, the object of any judgment is just that portion of the then conceived world, just that 
fragment, that aspect, that element of a supposed reality, which is seized upon for the purposes of just this judgment. Only such a momentarily grasped fragment of the truth can possibly be present in any one moment of thought as the object of a single assertion. Now it is hard to say how within this arbitrarily chosen fragment itself there can still be room for the partial knowledge that is sufficient to give to the judgment its object, but insufficient to secure to the judgment its accuracy. If I aim at a mark with my gun, I can fail to hit it, because choosing and hitting a mark are totally distinct acts. But, in the judgment, choosing and knowing the object seem inseparable. No doubt somehow our difficulty is soluble, but we are here trying first to show that it is a difficulty.

To illustrate here by a familiar case, when we speak of things that are solely matters of personal preference, such as the pleasure of a sleigh-ride, the taste of olives, or the comfort of a given room, and when we only try to tell how these things appear to us, then plainly our judgments, if sincere, cannot be in error. As these things are to us, so they are. We are their measure. To doubt our truthfulness in these cases is to doubt after the fashion of the student who wondered whether the star that the astronomers call Uranus may not be something else after all, and not really Uranus. Surely science does not progress very far or run into great danger of error so long as it employs itself in discovering such occult mysteries as the names of the stars. But our present question is, How do judgments that can be and that are erroneous differ in nature from these that cannot be erroneous? If astronomers would be equally right in case they should agree to call Uranus Humpty Dumpty, why are not all judgments equally favored? Since the judgment chooses its own object, and has it only in so far as it chooses it, how can it be in that partial relation to its object which is implied in the supposition of an erroneous assertion?

Yet again, to illustrate the difficulty in another aspect, we can note that not only is error impossible about the perfectly wellknown, but that error is equally impossible, save in the form of direct self-contradiction, about what is absolutely unknown. Spite of the religious awe of some people in presence of the Unknowable, it is safe to say, somewhat irreverently, that about a really Unknowable nobody could make any sincere and self-consistent assertions that could be errors. For self-consistent assertions about the Unknowable would of necessity be meaningless. And being 
meaningless, they could not well be false. For instance, one could indeed not say that the Unknowable contemplates war with France, or makes sunspots, or will be the next Presidential candidate, because that would be contradicting one's self. For if the Unknowable did any of these things, it would no longer be the Unknowable, but would become either the known or the discoverable. But avoid such self-contradiction, and you cannot err about the Unknowable. For the Unknowable is simply our old friend Abracadabra, a word that has no meaning, and by hypothesis never can get any. So if I say that the Unknowable dines in vacuo with the chimera, or is Humpty Dumpty, I talk nonsense, and am therefore unable to make a mistake. Nonsense is error only when it involves self-contradiction. Avoid that, and nonsense cannot blunder, having no object outside of itself with which it must agree. But all this illustrates from the other side our difficulty. Is not the object of a judgment, in so far as it is unknown to that judgment, like the Unknowables for that judgment? To be in error about the application of a symbol, you must have a symbol that symbolizes something. But in so far as the thing symbolized is not known through the symbol, how is it symbolized by that symbol? Is it not, like the Unknowable, once for all out of the thought, so that one cannot just then be thinking about it at all, and so cannot, in this thought at least, be making blunders about it? But in so far as the thing symbolized is, through the symbol, in one's thought, why is it not known, and so correctly judged? All this involves that old question of the nature of symbols. They are to mean for us more than we know that they mean. How can that be? No doubt all that is really possible, but how?

IV

We follow our difficulty into another department. Let us attempt a sort of provisional psychological description of a judgment as a state of mind. So regarded, a judgment is simply a fact that occurs in somebody's thought. If we try to describe it as an occurrence, without asking whence it came, we shall perhaps find in it three elements,-elements which are in some fashion described in Ueberweg's well-known definition of a judgment as the "Consciousness about the objective validity of a subjective union of ideas." Our interpretation of them shall be this: The elements are: The Subject, 
with the accompanying shade of curiosity about it; the Predicate, with the accompanying sense of its worth in satisfying a part of our curiosity about the subject; and the Sense of Dependence, whereby we feel the value of this act to lie, not in itself, but in its agreement with a vaguely felt Beyond, that stands out there as Object.

Now this analysis of the elements of a judgment is no explanation of our difficulties; and in fact for the moment only embarrasses us more. But the nature of the difficulty may come home to us somewhat more clearly, if we try to follow the thread of this analysis a little further. Even if it is a very imperfect account, it may serve to lead us up to the true insight that we seek into the nature of error. Let us make the analysis a little more detailed.

In its typical form then, the judgment as a mental state seems to us to begin with a relatively incomplete or unstable or disconnected mass of consciousness, which we have called the Subject, as it first begins to be present to us. This subject-idea is attended by some degree of effort, namely, of attention, whose tendency is to complete this incomplete subject by bringing it into closer connection with more familiar mental life. This more familiar life is represented by the predicate-idea. If the effort is successful, the subject has new elements united to it, assumes in consciousness a definiteness, a coherency with other states, a familiarity, which it lacked at the outset of the act of judgment; and this coherency it gets through its union with the predicate. All this is accompanied further by what one for short may call a sense of dependence. The judgment feels itself not alone, but looks to a somewhat indefinite object as the model after which the present union of ideas is to be fashioned. And in this way we explain how the judgment is, in those words of Ueberweg's definition, "the consciousness about the objective validity of a subjective union of ideas."

Now as a mere completion of subject-idea through the addition of a predicate-idea, the judgment is simply a mental phenomenon, having interest only to the person that experiences it, and to a psychologist. But as true or as false the judgment must be viewed in respect to the indefinite object of what we have called the sense of dependence, whereby the judgment is accompanied. Seldom in any ordinary judgment does this object become perfectly full and clear; for to make it so would often require many, perhaps an infinite, series of judgments. Yet, for the one judgment, the object, whether full and clear or not, exists as object only in so far forth as 
the sense of dependence has defined it. And the judgment is true or false only with reference to this undefined object. The intention to agree with the object is contained in the sense of dependence upon the object, and remains for this judgment incomplete, like the object itself. Somewhat vaguely this single act intends to agree with this vague object.

Such being the case, how can the judgment, as thus described, fairly be called false? As mere psychological combination of ideas it is neither true nor false. As accompanied by the sense of dependence upon an object, it would be false if it disagreed with its imperfectly defined object. But, as described, the only object that the judgment has is this imperfectly defined one. With this, in so far as it is for the moment defined, the judgment must needs agree. In so far as it is not defined, it is however not object for this judgment at all, but for some other one. What the imperfect sense of dependence would further imply if it existed in a complete instead of in an incomplete state, nobody can tell, any more than one can tell what towns would grow up by a given rain-pool, if it were no pool, but a great lake. The object of a single judgment, being what it is, namely, a vaguely defined object, present to this judgment, is just what it is for this judgment, and the judgment seems once for all to be true, in case it is sincere.

Some one may here at once answer that we neglect in this description the close interdependence of various judgments. Thought, some one may say, is an organic unity. Separated from all else but its own incompletely defined object, a single judgment cannot be erroneous. Only in the organic unity of a series of judgments, having a common object, is the error of one of them possible. We reply that all this will turn out to be just our result. But the usual supposition at the outset is that any judgment has by itself its own object, so that thereby alone, apart from other judgments, it stands or falls. And thus far we have tried to show that this natural supposition leads us into difficulty. We cannot see how a single sincere judgment should possibly fail to agree with its own chosen object. But enough of our problem in general. We must consider certain classes of errors more in detail. Let us see how, in these special classes of cases, we shall succeed in verifying the natural presupposition of common sense, which regards error as possible only when our object is not wholly present to mind, and which assumes that a judgment can have an object that is yet only partially 
present to mind. In choosing the classes of cases, we shall first follow common sense as to their definition. We shall take just the assumptions of daily life, and shall show that they lead us into difficulty. We are not for the first bound to explain why these assumptions are made. That common sense makes them is enough.

But let the reader remember: The whole value of our argument lies in its perfect generality. However much we dwell on particular classes of errors, we care nothing for the proof that just those errors are inexplicable, but only for the fact that they illustrate how, without some entirely new hypothesis, absolutely all error becomes impossible. This or that class of judgments may be one in which all the judgments are relative, but the total relativity of our thought implies an incomprehensible and contradictory state of things. Any hypothesis about error that makes total relativity the only admissible view, must therefore give place to some new hypothesis. And our illustrations in the following are intended to show that just what constitutes the difficulty in respect of these illustrations, makes the existence of any error inexplicable without some new hypothesis.

\section{$\mathbf{V}$}

The class of errors that we shall first take seems, to common sense, common enough. It is the class known as errors about our neighbor's states of mind. Let us then, for argument's sake, assume without proof that our neighbors do exist. For we are not here concerned to answer Solipsism, but merely to exemplify the difficulties about the nature of error. If our neighbors did not exist, then the nature of the error that would lie in saying that they do exist would present almost exactly the same difficulties. We prefer, however, to begin with the common-sense assumption about ourselves and our neighbors as separate individuals, and to ask how error can then arise in judging of our neighbors' minds.

In the first place then: Who is my neighbor? Surely, on the assumptions that we all make, and that we made all through the ethical part of our discussion, he is no one of my thoughts, nor is any part of him ever any part of my thought. He is not my object, but, in Professor Clifford's phrase, an "eject," wholly outside of my ideas. He is no "thing in my dream," just as I am not in his dream. 
Yet I make judgments about him, and he makes them about me. And when I make judgments about him, I do so by having in my thought some set of my own ideas that, although not himself, do yet, as I say, represent him. A kind of dummy, a symbol, a graven image of my own thought's creation, a phantom of mine, stands there in me as the representative of his mind; and all I say about my neighbor's inner life rofers directly to this representative. The Scottish philosophy has had much to say to the world about what it calls direct or presentative, as opposed to representative, knowledge of objects. But surely the most obstinate Scottish philosopher that ever ate oatmeal cannot hold so tenaciously by his national doctrine as to say that I have, according to common sense, anything but a representative knowledge of my neighbor's thoughts and feelings. That is the only sort of knowledge that common sense will regard as possible to me, if so much as that is possible. But how I can know about this outside being is not now our concern. We notice only that our difficulty about error comes back to us in a new form. For how can I err about my neighbor, since, for this common-sense view, he is not even partly in my thoughts? How can I intend that as the object of my thought which never can be object for me at all?

But not everybody will at once feel the force of this question. We must be more explicit. Let us take the now so familiar suggestion of our great humorist about the six people that take part in every conversation between two persons. If John and Thomas are talking together, then the real John and Thomas, their respective ideas of themselves, and their ideas of each other, are all parties to the conversation. Let us consider four of these persons, namely, the real John, the real Thomas, John as Thomas conceives him, and Thomas as John conceives him. When John judges, of whom does he think? Plainly of that which can be an object to his thoughts, namely, of bis Thomas. About whom then can he err? About bis Thomas? No, for he knows him too well. His conception of Thomas is his conception, and what he asserts it to be, that it is for him. About the real Thomas? No, for it should seem, according to common sense, that he has nothing to do with the real Thomas in his thought, since that Thomas never becomes any part of his thought at all. "But," says one, "there must be some fallacy here, since we are sure that John can err about the real Thomas." Indeed he can, say we; but ours is not this fallacy. Common sense 
has made it. Common sense has said: "Thomas never is in John's thought, and yet John can blunder about Thomas." How shall we unravel the knot?

One way suggests itself. Mayhap we have been too narrow in our definition of object. Common sense surely insists that objects are outside of our thought. If, then, I have a judgment, and another being sees both my judgment and some outside object that was not in my thought, and sees how that thought is unlike the object in some critical respect, this being could say that my assertion was an error. So then with John and Thomas. If Thomas could know John's thoughts about bim, then Thomas could possibly see John's error. That is what is meant by the error in John's thought.

But mere disagreement of a thought with any random object does not make the thought erroneous. The judgment must disagree with its chosen object. If John never has Thomas in thought at all, how can John choose the real Thomas as his object? If I judge about a penholder that is in this room, and if the next room is in all respects like this, save for a penholder in it, with which my assertion does not agree, who, looking at that penholder in that other room, can say that my judgment is false? For I meant not that penholder when I spoke, but this one. I knew perhaps nothing about that one, had it not in mind, and so could not err about it. Even so, suppose that outside of John there is a real Thomas, similar, as it happens, to John's ideal Thomas, but lacking some thought or affection that John attributes to his ideal Thomas. Does that make John's notion an error? No, for he spoke and could speak only of his ideal Thomas. The real Thomas was the other room, that he knew not of, the other side of the shield, that he never could conceive. His Thomas was his phantom Thomas. This phantom it is that he judges and thinks about, and his thoughts may have their own consistency or inconsistency. But with the real other person they have nothing to do. The real other is not his object, and how can he err about what is not object for him?

Absurd, indeed, some one will reply to us. John and Thomas have to deal with representative phantoms of each other, to be sure; but that only makes each more apt to err about the real other. And the test that they can err is a very simple one. Suppose a spectator, a third person, to whom John and Thomas were both somehow directly present, so that he as it were included both of them. Then John's judgment of his phantom Thomas would be by 
this spectator at once compared with the real Thomas, and even so would Thomas's judgment of John be treated. If now John's phantom Thomas agreed with the real Thomas, then John's ideas would be declared in so far truthful; otherwise they would be erroneous. And this explains what is meant by John's power to err about Thomas.

The explanation is fair enough for its own purpose, and we shall need it again before long. But just now we cannot be content with it. For what we want to know is not what the judgment of a third thinker would be in case these two were somehow not independent beings at all, but things in this third being's thought. For we have started out with the supposition of common sense that John and Thomas are not dreams or thoughts of some higher third being, but that they are independent beings by themselves. Our supposition may have to be given up hereafter, but for the present we want to hold fast to it. And so John's judgment, which we had supposed to be about the independently existing Thomas, has now turned out to be only a judgment about John's idea of Thomas. But judgments are false only in case they disagree with their intended objects. What, however, is the object of John's judgment when he thinks about Thomas? Not the real Thomas, who could not possibly be an object in another man's thoughts. John's real object being an ideal Thomas, he cannot, if sincere, and if fully conscious of what he means by Thomas, fail to agree in his statements with his own ideal. In short, on this our original supposition, John and Thomas are independent entities, each of which cannot possibly enter in real person into the thoughts of the other. Each may be somehow represented in the other's thoughts by a phantom, and only this phantom can be intended by the other when he judges about the first. For unless one talks nonsense, it should seem as if one could mean only what one has in mind.

Thus, like the characters in a certain Bab ballad, real John, real Thomas, the people in this simple tale, are total strangers to each other. You might as well ask a blind man to make true or false judgments about the real effects of certain combinations of colors, as to ask either John or Thomas, defined as common sense defines them, to make any judgments about each other. Common sense will assert that a blind man can learn and repeat verbally correct statements about color, or verbally false statements about color, but, according to the common-sense view, in no case can he err 
about color-ideas as such, which are never present to him. You will be quite ready to say that a dog can make mistakes about the odors of the numberless tracks on the highway. You will assure us, however, that you cannot make mistakes about them because these odors do not exist for you. According to the common-sense view, a mathematician can make blunders in demonstrating the properties of equations. A Bushman cannot, for he can have no ideas corresponding to equations. But how then can John or Thomas make errors about each other, when neither is more present to the other than is color to the blind man, the odor of the tracks on the highway to the dog's master, or the idea of an equation to a Bushman? Here common sense forsakes us, assuring us that there is such error, but refusing to define it.

The inconsistency involved in all this common-sense view, and the consequences of the inconsistency, will appear yet better with yet further illustration. A dream is false in so far as it contains the judgment that such and such things exist apart from us; but at least in so far as we merely assert in our dreams about the objects as we conceive them, we make true assertions. But is not our actual life of assertions about actual fellow-beings much like a dream to which there should happen to correspond some real scene or event in the world? Such correspondence would not make the dream really "true," nor yet false. It would be a coincidence, remarkable for an outside observer, but none the less would the dreamer be thinking in his dream not about external objects, but about the things in his dream. But is not our supposed Thomas so and only so in the thought of John as he would be if John chanced to dream of a Thomas that was, to an external spectator, like the real one? Is not then the phantom Thomas, John's only direct object, actually a thing in John's thought? Is then the independent Thomas an object for John in any sense?

Yet again. Let us suppose that two men are shut up, each in a closed room by himself, and for his whole life; and let us suppose that by a lantern contrivance each of them is able at times to produce on the wall of the other's room a series of pictures. But neither of them can ever know what pictures he produces in the other's room, and neither can know anything of the other's room, as such, but only of the pictures. Let the two remain forever in this relation. One of them, A, sees on his wall pictures, which resemble more or less what he has seen in his own room at other times. Yet 
he perceives these to be only pictures, and he supposes them to represent what goes on in another room, which he conceives as like his own. He is interested, he examines the phenomena, he predicts their future changes, he passes judgment upon them. He may, if you like to continue the hypothesis, find some way of affecting them, by himself acting in a way mysterious to himself so as to produce changes in B's actual room, which again affect the pictures that the real B produces in A's room. Thus A might hold what he would call communication with his phantom room. Even so, $\mathrm{B}$ lives with pictures before him that are produced from A's room. Now one more supposition, namely, that A and B have absolutely no other means of communication, that both are shut up altogether and always have been, that neither has any objects before him but his own thoughts and the changing pictures on the wall of his room. In this case what difference does it make whether or no the pictures in A's room are actually like the things that could be seen in B's room? Will that make A's judgments either true or false? Even if A, acting by means that he himself cannot understand, is able to control the pictures on his wall by some alteration that he unconsciously produces in B's room and its pictures, still A cannot be said to have any knowledge of the real B and his room at all. And, for the same reason, A cannot make mistakes about the real room of $\mathrm{B}$, for he will never even think of that real room. He will, like a man in a dream, think and be able to think only of the pictures on his wall. And when he refers them to an outside cause, he does not mean by this cause the real $\mathrm{B}$ and his real room, for he has never dreamed of the real B, but only of the pictures and of his own interpretation of them. He can therefore make no false judgments about B's room, any more than a Bushman can make false judgments about the integral calculus.

If to our present world there does correspond a second world somewhere off in space, a world exactly like this, where just the same events at every instant do actually take place, still the judgments that we make about our world are not actually true or false with reference to that world, for we mean this world, not that one, when we judge. Why are not John's Thomas and the real Thomas related like this world and that second world in distant space? Why are not both like the relation of A's conceived phantom room and B's real room? Nothing of either real room is ever pres- 
ent to the other. Each prisoner can make true or false judgments if at all, then, only about the pictures on his wall; but neither has even the suggestion that could lead him to make a blunder about the other's real room, of which he has and can have not the faintest idea.

One reason why we fail to see at once this fact lies in the constant tendency to regard the matter from the point of view of a third person, instead of from the point of view that we still implicitly attribute to A and B themselves. If A could get outside of his room once and see B's room, then he could say: "My picture was a good one," or the reverse. But, in the supposed case, he not only never sees B's room, but he never sees anything but his own pictures, never gets out of his room at all for any purpose. Hence, his sole objects of assertion being his pictures, he is innocent of any power to err about B's room as it is in itself, even as the man born blind is innocent of any power to err about the relations of colors. Now this relation of $\mathrm{A}$ and $\mathrm{B}$, as they were supposed to dwell in their perpetual imprisonment, is essentially like the relation that we previously postulated between two independent subjects. If I cannot have you in my thought at all, but only a picture produced by you, I am in respect to you like A confined to the pictures produced from B's room. However much I may fancy that I am talking of you, I am really talking about my idea of you, which for me can have no relation whatever to the real you. And so John and Thomas remain shut up in their prisons. Each thinks of his phantom of the other. Only a third person, who included them both, who in fact treated them as, in the Faust-Epilogue, the Pater Seraphicus treats the selige Knaben (Er nimmt sie in sich, says the stage direction)-only such an inclusive thought could compare the phantoms with the real, and only in him, not in themselves, would John and Thomas have any ideas of each other at all, true or false.

This result is foreign to our every-day thought, because this every-day thought really makes innocent use of two contradictory views of the relations of conscious beings. On the one hand we regard them as utterly remote from one another, as what Professor Clifford called ejects; and then we speak of them as if the thoughts of one could as such become thoughts of the other, or even as if one of them could as an independent being still become object in the thought of the other. No wonder that, with such contradictory assumptions as to the nature of our relations to our neighbors, we 
find it very easy to make absurd statements about the meaning of error. The contradiction of common sense has in fact just here much to do with the ethical illusion that we called the illusion of selfishness. To clear up this point will be useful to us, therefore, in more ways than one.

\section{VI}

Disappointed once more in our efforts to understand how error is possible, we turn to another class of cases, which lie in a direction where, at least for this once, all will surely be plain. Errors about matters of fact or experience are certainly clear enough in nature. And as this class of errors is practically most important, the subtleties of our previous investigation may be dismissed with light heart so soon as we have gotten rid of the few little questions that will now beset us. It is to be noted that all errors about material objects, about the laws of nature, about history, and about the future, are alike errors about our actual or possible experiences. We expect or postulate an experience that at the given time, or under the given conditions, turns out to be other than it was postulated or expected to be. Now since our experiences not now present are objective facts, and capable of clear definition, it would seem clear that error concerning them is an easily comprehensible thing.

But alas! again we are disappointed. That errors in matters of experience are common enough is indubitable, but equally evident becomes the difficulty of defining what they are and how they are possible. Take the case of error about an expected future. What do we mean by a future time? How do we identify a particular time? Both these questions plunge us into the sea of problems about the nature of time itself. When I say, Thus and so will it be at such and such a future moment, I postulate certain realities not now given to my consciousness. And singular realities they are. For they have now no existence at all. Yet I postulate that I can err about them. Thus their non-existence is a peculiar kind of non-existence, and requires me to make just such and such affirmations about it. If I fail to correspond to the true nature of this non-existent reality, I make an error; and it is postulated not merely that my present statement will in that case hereafter turn out false or become false, but also that it is now false, is at this moment an error, even though the real- 
ity with which it is to agree is centuries off in the future. But this is not all the difficulty. I postulate also that an error in prediction can be discovered when the time comes by the failure of the prediction to verify itself. I postulate then that I can look back and say: Thus and thus I predicted about this moment, and thus and thus it has come to pass, and this event contradicts that expectation. But can I in fact ever accomplish this comparison at all? And is the comparison very easily intelligible? For when the event comes to pass, the expectation no longer exists. The two thoughts, namely, expectation and actual experience, are separate thoughts, far apart in time. How can I bring them together to compare them, so as to see if they have the same object? It will not do to appeal to memory for the purpose; for the same question would recur about the memory in its relation to the original thought. How can a past thought, being past, be compared to a present thought to see whether they stand related? The past thought lived in itself, had its own ideas of what it then called future, and its own interpretation thereof. How can you show, or intelligently affirm, that the conception which the past expectation had of its future moment is so identical with the conception which this present thought has of this present moment, as to make these two conceived moments one and the same? Here in short we have supposed two different ideas, one of an expected future, the other of an experienced present, and we have supposed the two ideas to be widely separated in time, and by hypothesis they are not together in one consciousness at all. Now how can one say that in fact they relate to the same moment at all? How is it intelligible to say that they do? How, in fine, can a not-given future be a real object of any thought; and how, when it is once the object thereof, can any subsequent moment be identified with this object?

A present thought and a past thought are in fact separate, even as were John and Thomas. Each one means the object that it thinks. How can they have a common object? Are they not once for all different thoughts, each with its own intent? But in order to render intelligible the existence of error about matters of fact, we must make the unintelligible assumption, so it would seem, that these two different thoughts have the same intent, and are but one. And such is the difficulty that we find in our second great class of cases. 


\section{VII}

So much for the problem, both in general and in some particular instances. But now may not the reader insist, after all, that there can be in this wise no errors whatever? Contradictory as it seems, have we not, after all, put our judgments into a position whence escape for us is impossible? If every judgment is thus by its nature bound up in a closed circle of thought, with no outlook, can any one come afterwards and give it an external object? Perhaps, then, there is a way out of our difficulty by frankly saying that our thoughts may be neither truths nor errors beyond themselves, but just occurrences, with a meaning wholly subjective.

We desire the reader to try to realize this view of total relativity once more in the form in which, with all its inherent absurdities, it now comes back to us for the last time. It says, "Every judgment, $A$ is $B$, in fact does agree and can agree only with its own object, which is present in mind when it is made. With no external object can it agree or fail to agree. It stands alone, with its own object. It has neither truth nor error beyond itself. It fulfills all its intentions, and is true, if it agrees with what was present to it when it was thought. Only in this sense is there any truth or falsity possible for our thought."

But once more, this inviting way out of the difficulty needs only to be tried to reveal its own contradictions. The thought that says, "No judgment is true beyond itself," is that thought true beyond itself or not? If it is true beyond itself, then we have the possibility of other truth than the merely subjective or relative truth. If it is false, then equally we have objective falsity. If it is neither true nor false, then the doctrine of relativity has not been affirmed at all as a truth. One sets up an idea of a world of separate, disorganized thoughts, and then says, "Each of them deals only with its own object, and they have no unity that could make them true or false." But still this world that one thus sets up must be the true world. Else is there no meaning in the doctrine of relativity. Twist as one will, one gets not out of the whirlpool of thought. Error must be real, and yet, as common sense arranges these judgments and their relations to one another, error cannot be real. There is so far no escape.

The perfectly general character of the argument must be understood. One might escape it if it applied to any one class of errors 
only. Then one would say: "In fact, the class of cases in question may be cases that exclude the possibility of both truth and error." But no, that cannot be urged against us, for our argument applies equally to all possible errors. In short, either no error at all is possible, or else there must be possible an infinite mass of error. For the possibilities of thought being infinite, either all thought is excluded once for all from the possibility of error, or else to every possible truth there can be opposed an infinite mass of error. All this infinite mass is at stake upon the issue of our investigation. Total relativity, or else an infinite possibility of truth and error; that is the alternative before us. And total relativity of thought involves self-contradiction.

Every way but one has been tried to lead us out of our difficulty. Shall we now give up the whole matter, and say that error plainly exists, but baffles definition? This way may please most people, but the critical philosophy knows of no unanswerable problem affecting the work of thought in itself considered. Here we need only patience and reflection, and we are sure to be some day rewarded. And indeed our solution is not far off, but very nigh us. We have indicated it all along. To explain how one could be in error about his neighbor's thoughts, we suggested the case where John and Thomas should be present to a third thinker whose thought should include them both. We objected to this suggestion that thus the natural presupposition that John and Thomas are separate self-existent beings would be contradicted. But on this natural presupposition neither of these two subjects could become object to the other at all, and error would here be impossible. Suppose then that we drop the natural presupposition, and say that John and Thomas are both actually present to and included in a third and higher thought. To explain the possibility of error about matters of fact seemed hard, because of the natural postulate that time is a pure succession of separate moments, so that the future is now as future non-existent, and so that judgments about the future lack real objects, capable of identification. Let us then drop this natural postulate, and declare time once for all present in all its moments to an universal all-inclusive thought. And to sum up, let us overcome all our difficulties by declaring that all the many Beyonds, which single significant judgments seem vaguely and separately to postulate, are present as fully realized intended objects to the unity of an all-inclusive, absolutely clear, universal, and 
conscious thought, of which all judgments, true or false, are but fragments, the whole being at once Absolute Truth and Absolute Knowledge. Then all our puzzles will disappear at a stroke, and error will be possible, because any one finite thought, viewed in relation to its own intent, may or may not be seen by this higher thought as successful and adequate in this intent.

How this absolute thought is to be related to individual thoughts, we can in general very simply define. When one says: "This color now before me is red, and to say that it is blue would be to make a blunder," one represents an including consciousness. One includes in one's present thought three distinct elements, and has them present in the unity of a single moment of insight. These elements are, first, the perception of red; secondly, the reflective judgment whose object is this perception, and whose agreement with the object constitutes its own truth; and, thirdly, the erroneous reflection, This is blue, which is in the same thought compared with the perception and rejected as error. Now, viewed as separate acts of thought, apart from the unity of an including thought, these three elements would give rise to the same puzzles that we have been considering. It is their presence in a higher and inclusive thought that makes their relations plain. Even so we must conceive the relation of John's thought to the united total of thought that includes him and Thomas. Real John and his phantom Thomas, real Thomas and his phantom John, are all present as elements in the including consciousness, which completes the incomplete intentions of both the individuals, constitutes their true relations, and gives the thought of each about the other whatever of truth or of error it possesses. In short, error becomes possible as one moment or element in a higher truth, that is, in a consciousness that makes the error a part of itself, while recognizing it as error.

So far then we propose this as a possible solution for our puzzles. But now we may insist upon it as the only possible solution. Either there is no such thing as error, which statement is a flat self-contradiction, or else there is an infinite unity of conscious thought to which is present all possible truth. For suppose that there is error. Then there must be an infinite mass of error possible. If error is possible at all, then as many errors are possible as you please, since, to every truth, an indefinite mass of error may be opposed. Nor is this mere possibility enough. An error is possible for us when we 
are able to make a false judgment. But in order that the judgment should be false when made, it must have been false before it was made. An error is possible only when the judgment in which the error is to be expressed always was false. Error, if possible, is then eternally actual. Each error so possible implies a judgment whose intended object is beyond itself, and is also the object of the corresponding true judgment. But two judgments cannot have the same object save as they are both present to one thought. For as separate thoughts they would have separate subjects, predicates, intentions, and objects, even as we have previously seen in detail. So that every error implies a thought that includes it and the corresponding truth in the unity of one thought with the object of both of them. Only as present to an including thought are they either true or false. Thus then we are driven to assume an infinite thought, judging truth and error. But that this infinite thought must also be a rational unity, not a mere aggregate of truths, is evident from the fact that error is possible not only as to objects, but as to the relations of objects, so that all the possible relations of all the objects in space, in time, or in the world of the barely possible, must also be present to the all-including thought. And to know all relations at once is to know them in absolute rational unity, as forming in their wholeness one single thought.

What, then, is an error? An error, we reply, is an incomplete thought, that to a higher thought, which includes it and its intended object, is known as having failed in the purpose that it more or less clearly had, and that is fully realized in this higher thought. And without such higher inclusive thought, an assertion has no external object, and is no error.

\section{VIII}

If our argument were a Platonic dialogue, there would be hereabouts an interruption from some impatient Thrasymachus or Callicles or Polus, who would have been watching us, threatening and muttering, during all of the latter part of our discussion. At

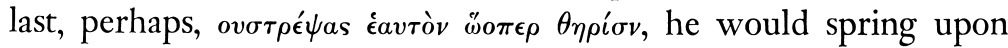
us, and would say: "Why, you nonsense-mongers, have you not bethought you of the alternative that represents the reality in this question of yours? Namely, an error is an error, neither to the thought that thinks it, nor of necessity to any higher inclusive 
thought, but only to a possible critical thought that should undertake afterwards to compare it with its object. An error is a thought such that if a critical thought did come and compare it with its object, it would be seen to be false. And it has an object for such a critical thought. This critical thought need not be real and actually include it, but may be only a possible judge of its truth. Hence your Infinite all-knower is no reality, only a logical possibility; and your insight amounts to this, that if all were known to an allknower, he would judge error to be mistaken. And so error is what he would perceive to be error. What does all that amount to but worthless tautology?"

This argument of our Thrasymachus is the only outwardly plausible objection that we fear to the foregoing analysis, because it is the only objection that fully expresses the old-established view of common sense about such problems. Though common sense never formulates our present difficulty, common sense still dimly feels that to some possible (not actual) judge of truth, appeal is made when we say that a thing is false not merely for us, but in very truth. And this possible judge of common sense we have now unhesitatingly declared to be an Infinite Actuality, absolutely necessary to constitute the relation of truth and error. Without it there is for our view no truth or error conceivable. The words, This is true, or This is false, mean nothing, we declare, unless there is the inclusive thought for which the truth is true, the falsehood false. No barely possible judge, who would see the error if he were there, will do for us. He must be there, this judge, to constitute the error. Without him nothing but total subjectivity would be possible; and thought would then become purely a pathological phenomenon, an occurrence without truthfulness or falsity, an occurrence that would interest anybody if it could be observed; but that, unfortunately, being only a momentary phantom, could not be observed at all from without, but must be dimly felt from within. Our thought needs the Infinite Thought in order that it may get, through this Infinite judge, the privilege of being so much as even an error.

This, it will be said, is but reassertion. But how do we maintain this view against our Thrasymachus? Our answer is only a repetition of things that we have already had to say, in the argument for what we here reassert. If the judgment existed alone, without the 
inclusive thought to judge it, then, as it existed alone, it either had an object, or had none. But if it had none, it was no error. If it had one, then either it knew what its object actually was, or it did not know what its object was, or it partially knew and partially did not know what its object actually was. In the first case the judgment must have been an identical one, like the judgment $A$ pain is a pain. Such a judgment knows its own object, therefore cannot fail to agree with it, and cannot be an error. If the judgment knew not its own object at all, then it had no meaning, and so could not have failed to agree with the object that it had not. If, however, this separate judgment knew its object enough to intend just that object, but not enough to insure agreement with it, all our difficulties return. The possible judge cannot give the judgment its complete object until he becomes its actual judge. Yet as fair judge he must then give it the object that it already had without him. Meanwhile, however, the judgment remains in the unintelligible attitude previously studied at length. It is somehow possessed of just the object it intends, but yet does not know in reality what it does intend, else it would avoid error. Its object, in so far as unknown to it, is no object for it; and yet only in so far as the object is thus unknown can it be erred about. What helps in all this the barely possible judge? The actual judge must be there; and for him the incomplete intention must be complete. He knows what is really this judgment's object, for he knows what is imperfectly meant in it. He knows the dream, and the interpretation thereof. $\mathrm{He}$ knows both the goal and the way thither. But all this is, to the separate judgment as such, a mystery.

In fact, the separate judgments, waiting for the possible judge to test them, are like a foolish man wandering in a wood, who is asked whether he has lost his way. "I may have lost it," he answers. "But whither are yoù going?" "That I cannot tell." "Have you no goal?" "I may have, but I have no notion what it is." "What then do you mean by saying that you may have lost the way to this place that you are not seeking? For you seem to be seeking no place; how then can you have lost the way thither?" "I mean that some possible other man, who was wise enough to find whither I am trying to go, might possibly, in his wisdom, also perceive that I am not on the way to that place. So I may be going away from my chosen goal, although I am unaware what goal it is that I have 
chosen." Such a demented man as this would fairly represent the meaningless claim of the separate judgment, either to truthfulness, or to the chance of error.

In short, though the partial thought may be, as such, unconscious of its own aim, it can be so unconscious only in case it is contained in a total thought as one moment thereof.

It will be seen that wherever we have dealt in the previous argument with the possibility of error as a mere possibility, we have had to use the result of the previous chapter concerning the nature of possibility itself. The idea of the barely possible, in which there is no actuality, is an empty idea. If anything is possible, then, when we say so, we postulate something as actually existent in order to constitute this possibility. The conditions of possible error must be actual. Bare possibility is blank nothingness. If the nature of error necessarily and with perfect generality demands certain conditions, then these conditions are as eternal as the erroneousness of error itself is eternal. And thus the inclusive thought, which constitutes the error, must be postulated as existent.

So, finally, let one try to affirm that the infinite content of the all-including mind does not exist, and that the foregoing idealism is a mere illusion of ours. He will find that he is involved in a circle from which there is no escape. For let him return to the position of total relativity and so say: "The infinite thought is unreal for me, and hence you are wrong." But then also he admits that we are right, for in affirming this infinite we affirm, according to this doctrine of total relativity itself, something that is just as true as it seems to us to be true. The opposing argument is thus at each moment of its progress involved in a contradiction. Or again, let him insist that our doctrine is not only relatively, but really false. Then however he will fail to show us what this real falsity is. In fact he says what all our previous examination shows to mean, this, namely, that an infinite thought does exist, and does experience the truth, and compares our thought with the truth, and then observes this thought of ours to be false, that is, it discovers that itself is non-existent. Whoever likes this result may hold it if he can.

IX

Now that our argument is completed as an investigation, let us review it in another way. We started from the fact of Error. That 
there is error is indubitable. What is, however, an error? The substance of our whole reasoning about the nature of error amounted to the result that in and of itself alone, no single judgment is or can be an error. Only as actually included in a higher thought, that gives to the first its completed object, and compares it therewith, is the first thought an error. It remains otherwise a mere mental fragment, a torso, a piece of drift-wood, neither true nor false, objectless, no complete act of thought at all. But the higher thought must include the opposed truth, to which the error is compared in that higher thought. The higher thought is the whole truth, of which the error is by itself an incomplete fragment.

Now, as we saw with this as a starting-point, there is no stoppingplace short of an Infinite Thought. The possibilities of error are infinite. Infinite then must be the inclusive thought. Here is this stick, this brickbat, this snow-flake: there is an infinite mass of error possible about any one of them, and notice, not merely possible is it, but actual. All the infinite series of blunders that you could make about them not only would be blunders, but in very truth now are blunders, though you personally could never commit them all. You cannot in fact make a truth or a falsehood by your thought. You only find one. From all eternity that truth was true, that falsehood false. Very well then, that infinite thought must somehow have had all that in it from the beginning. If a man doubts it, let him answer our previous difficulties. Let him show us how he can make an error save through the presence of an actual inclusive thought for which the error always was error and never became such at all. If he can do that, let him try. We should willingly accept the result if he could show it to us. But he cannot. We have rambled over those barren hills already too long. Save for Thought there is no truth, no error. Save for inclusive Thought, there is no truth, no error, in separate thoughts. Separate thoughts as such cannot then know or have the distinction between their own truth and their own falsity in themselves, and apart from the inclusive thought. There is then nothing of truth or of error to be found in the world of separate thoughts as such. All the thoughts are therefore in the last analysis actually true or false, only for the all-including Thought, the Infinite.

We could have reached the same result had we set out from the problem, What is Truth? We chose not to do so because our skepticism had the placid answer ready: "No matter what truth is, for 
very likely there is little or no truth at all to be had. Why trouble one's mind to define what a fairy or a brownie is?" "Very well, then," we said to our skepticism, "if that is thy play, we know a move that thou thinkest not of. We will not ask thee of truth, if thou thinkest there is none. We will ask thee of error, wherein thou revelest." And our skepticism very cheerfully, if somewhat incoherently, answers, that, "if there be little or no truth here below, there is at least any amount of error, which as skeptics we have all been detecting ever since we first went to school." "We thank thee for that word, oh friend, but now, what is an error?" Blessed be Socrates for that question. Upon that rock philosophy can, if it wants, build we know not yet how much.

It is enough for the moment to sum up the truth that we have found. It is this: "All reality must be present to the Unity of the Infinite Thought." There is no chance of escape. For all reality is reality because true judgments can be made about it. And all reality, for the same reason, can be the object of false judgments. Therefore, since the false and the true judgments are all true or false as present to the infinite thought, along with their objects, no reality can escape. You and I and all of us, all good, all evil, all truth, all falsehood, all things actual and possible, exist as they exist, and are known for what they are, in and to the absolute thought; are therefore all judged as to their real character at this everlasting throne of judgment.

This we have found to be true, because we tried to doubt everything. We shall try to expound in the coming chapter the religious value of the conception. We can however at once see this in it: The Infinite Thought must, knowing all truth, include also a knowledge of all wills, and of their conflict. For him all this conflict, and all the other facts of the moral world, take place. He then must know the outcome of the conflict, that Moral Insight of our first book. In him then we have the Judge of our ideals, and the Judge of our conduct. He must know the exact value of the Good Will, which for him, like all other possible truth, must be an actually realized Fact. And so we cannot pause with a simply theoretical idealism. Our doctrine is practical too. We have found not only an infinite Seer of physical facts, but an infinite Seer of the Good as well as of the Evil. He knows what we have and what we lack. In looking for goodness we are in no wise looking for what the real world does not contain. 
This, we say, we have found as a truth, because we tried to doubt everything. We have taken the wings of the morning, and we have fled; but behold, we are in the midst of the Spirit. Truly the words that some people have thought so fantastic ought henceforth to be put in the text-books as commonplaces of logical analysis:-

They reckon ill that leave me out; When me they fly, I am the wings, I am the doubter and the doubt.-

Everything finite we can doubt, but not the Infinite. That eludes even our skepticism. The world-builders, and the theodicies that were to justify them, we could well doubt. The apologetic devices wearied us. All the ontologies of the realistic schools were just pictures, that we could accept or reject as we chose by means of postulates. We tried to escape them all. We forsook all those gods that were yet no gods; but here we have found something that abides, and waxes not old, something in which there is no variableness, neither shadow of turning. No power it is to be resisted, no plan-maker to be foiled by fallen angels, nothing finite, nothing striving, seeking, losing, altering, growing weary; the All-Enfolder it is, and we know its name. Not Heart, nor Love, though these also are in it and of it; Thought it is, and all things are for Thought, and in it we live and move. 
